\title{
Main Direction of Risk Mitigation in Petroleum Industry: Researches of IPGG SB RAS
}

\author{
Igor Yeltsov, Anna Komarova
}

Trofimuk Institute of Petroleum Geology and Geophysics of SB RAS, 630090, Novosibirsk, Russia doi: https://doi.org/10.21467/abstracts.93.91

\begin{abstract}
Introduction. Petroleum industry is considered one of the largest in the world, however at the same time one of most risky. The risks are mainly associated with the probabilistic nature of most of the technical and economic indicators of the development of oil and gas fields; climate and landscape conditions, time variability of natural factors; long duration of oil and gas projects; vast environmental impact of all sectors of the industry. Main trends of the petroleum industry have been changing drastically during the past decades. The industry is facing slow depletion of conventional resources; thus, one of the main direction of development is exploration and production of unconventional oil and gas, as well as resources and reserves in hard-to-access areas. Another challenge for the petroleum sector of particular country is competition, both between different energy sources and different regions. All of the above proves the growing need for the methods of cost optimization, increasing efficiency and risk mitigation. IPGG SB RAS supports research in a number of directions of risk mitigation, including geological, production and transportation, emergency, ecological and economical risks.
\end{abstract}

Geological risks. Exploration of oil and gas resources associated with large risks of insufficient study of the total and recoverable reserves of oil and gas fields, lack of exploration and geophysical research information on reservoir properties of the reservoir, etc. Advanced methods of exploration and interpretation of data allows for the increase in accuracy of estimations. Processing algorithms for highfrequency induction resistivity data can be applied to log data acquired at different stages of well construction. Open-hole induction logging while reaming of vertical wells provides a priori information on geology and resistivity distribution. Algorithms for inversion of high-frequency induction responses from layered media are used in a software package for processing LWD data. The specially developed software provides real-time inversion to recover resistivities and depths to layers in oil and gas reservoirs penetrated by wells of a complex trajectory.

Production and transportation risks. Risks in the production area include ineffective use of resources, a possible drop in production volumes, an increase in the cost of production. As a result, there is a possibility of irrational development of the field and its earlier development. Promising direction of research is construction of the digital oilfields, which simulate the structure of an actual field and gives an opportunity to compare different scenarios of exploration and development. Moreover, it is possible to reconstruct the formation of the particular rift during the movements of the earth's crust. The quality of the upper soil layer can provide additional risks to the production and transportation process. The technology of mechanized processing of local sandy soils that do not have conditioning building properties with reinforcing cryogelite compounds can be used in the construction of roads and engineering structures. Methodology for operational monitoring of the condition of soil treated with cryogelite reinforcing compounds using geophysical methods (such as shallow electrical exploration) provides long term supervision.

Emergency risks. Emergency risks for the industry include all types of force majeure, including natural disasters (earthquakes, floods, etc.), conflicts (war zones, political instability, etc.), technical emergencies

(C) 2020 Copyright held by the author(s). Published by AIJR Publisher in "Abstracts of The Second Eurasian RISK-2020 Conference and Symposium" April 12- 19, 2020, Tbilisi, Georgia. Jointly organized by AMIR Technical Services LLC, Georgian Technical University, Institute of Geography (Kazakhstan) and Russian Institute of Petroleum Geology and Geophysics.

AijR DOI: $10.21467 /$ abstracts. 93 
The Second Eurasian RISK-2020 Conference and Symposium

(blowouts, accidents, etc.) One of the areas that can be advanced with the help of geophysical research is study and prediction of seismic activity. Development of the seismic tomography method and its application for the study of various geological structures has provided world renown results. The created LOTOS passive tomography algorithm has already been tested on more than a hundred objects around the world and served as the basis for construction scenarios for the development of various geological structures.

The use of the flexural standing wave method allows for solving seismic engineering problems, such as microseismic zoning, underground mapping, piping diagnostics, seismic safety of facilities, pavement diagnostics.

Ecological risks. Petroleum industry is often considered one of the main pollutants in the world with all of its sectors adding to the water, air, soil contamination. Nowadays most of the states and companies turn to the "greener" technologies, however there is still need to handle previous pollutions, as well as prevent the future ones. Comprehensive assessment of technogenic deposits (waste from the mining industry) with the development of methods for the secondary processing of waste and the restoration of disturbed territories. Assessment includes technique for operational control of the efficiency of neutralization of waste from a zinc plant by methods of induced polarization and electrotomography; methodology for calculating tailings volumes using remote sensing data, seismotomography and electrotomography.

Another promising direction of research is development of a methodology for assessing environmental risks in oil-contaminated Arctic territory. It allows for evaluation of the pollution of environmental components in the area of mothballed oil and gas condensate fields with chemical elements and oil products, taking into account high concentrations of arsenic (hazard class 1), iron, manganese, typical of the Arctic territories.

Economical risks. Oil price is one of the most volatile indicators in the modern economy with a great influence on the different areas of state and companies' activities. Accurate assessment and forecast of the future revenues and costs for the company allows for the long-term planning of exploration and production operations. Complex evaluation of influence of state policy in petroleum industry provides basis for improvements of particular government measures to stimulate the development of the industry and regions. At the same time, such analysis reveals possible shortage of state budget in the future.

In conclusion, an integrated approach to risk accounting at all stages of subsoil use - the search, assessment, exploration and extraction of minerals - has been developed at the IPGG SB RAS. Thus, evaluations of the economic efficiency formed the basis for the formation of a number of strategic documents for the development of the oil and gas industry in Russia; geological assessment of oil and gas prospects made it possible to justify the priority areas of the exploration and production, including the Arctic shelf; geophysical tools and research methods correspond to breakthrough levels and compete with world analogues.

Funding. The study was financially supported by the RFBR (research project 18-310-20010). 